\title{
MFP14, a multifunctional emerging protein with immunomodulatory properties, prevents spontaneous and recurrent autoimmune diabetes in NOD mice
}

\author{
A. E. Panerai ${ }^{1}$, F. Nicoletti ${ }^{2}$, P.Sacedote ${ }^{1}$, L.Arvidsson ${ }^{3}$, I. Conget ${ }^{4}$, R. Gomis ${ }^{4}$, A. Bartorelli ${ }^{5}$, S.Sandler ${ }^{3}$ \\ ${ }^{1}$ Department of Pharmacology, University of Milan, Milan, Italy \\ ${ }^{2}$ Institute of Microbiology, University of Milan Bicocca, Milan, Italy \\ ${ }^{3}$ Department of Medical Cell Biology, Uppsala university, Uppsala, Sweden \\ ${ }^{4}$ Endocrinology and Nutrition Unit, Hospital Clinic of Barcelona, Villaroel, Barcelona, Spain \\ ${ }^{5}$ Institute of Researches Giorgio Sisini, University of Milan, Milan, Italy
}

\section{Abstract}

Aims/hypothesis. To test the effects of multifunctional protein 14 (MFP14), which shares structural homology with heat shock proteins (HSPs), on the development of Type I (insulin-dependent) diabetes mellitus in NOD mice.

Methods. MFP14 was given to euglycaemic female NOD mice from either the $4^{\text {th }}$ to the $25^{\text {th }}$ or from the $12^{\text {th }}$ until the $35^{\text {th }}$ week, or commencing one day before islet transplantation and until the reappearance of hyperglycaemia. Pancreata from NOD mice treated with multifunctional protein 14 for 14 consecutive weeks until 18 weeks of age were examined histologically for insulitis. Anti-CD3 and/or lipopolysaccharide (LPS)-induced blood levels of interferon (IFN)$\gamma$, interleukin (IL)-4, IL-10, IL-12 and tumour necrosis factor (TNF)- $\alpha$ were measured by ELISA in 10 week-old female NOD mice treated for 6 consecutive weeks with either MFP14 or PBS. Unless otherwise stated, multifunctional protein 14 was administered daily 5 times a week at a dose of $25 \mu \mathrm{g}$. Control mice received PBS or, in selected experiments, heat-inactivated MFP14.

Results. MFP 14 treated mice had a significantly lower incidence of spontaneous diabetes compared to control mice. The MFP14 was equally effective both upon early and late prophylaxis and the protection persisted until week 50 in mice treated from weeks 4 to 25. Insulitis was significantly reduced by the MFP14. The MFP14 also delayed recurrence of hyperglycaemia in syngeneic islet-transplanted NOD mice. Although MFP14 reduced anti-CD3 and/or LPS-induced blood levels of IFN- $\gamma$, TNF- $\alpha$ and IL12 it increased IL-4 and IL-10.

Conclusion/interpretation. The MFP14 could be a possible candidate for the prevention or early treatment of human Type I (insulin-dependent) diabetes mellitus. [Diabetologia (2001) 44: 839-847]

Keywords MFP14, NOD, Cytokines, TH1, TH2
The non obese diabetic (NOD) mouse shares clinical, serological and histoimmunological features with human Type I (insulin-dependent) diabetes mellitus [1, 2]. In particular, it was demonstrated that a peptide

Received: 2 November 2000 and in revised form: 14 February 2001

Corresponding author: Prof. Alberto Panerai, Via Vanvitelli 32, 20121 Milan, Italy

Abbreviations: HSP, heat shock protein; IL, interleukin; IFN, interferon; LPS, lipopolysaccharide; MFP14, multifunctional protein 14; hi, heat inactivated; NOD, non obese diabetic; ROD, recurrence of diabetes. containing epitope (named p277) of the heat shock protein (HSP) 60, the mammalian homologue of the mycobacterial HSP65 protein, is a key autoantigenic target in the pathogenesis of diabetes in NOD mouse [3]. The onset of the disease was associated with occurrence of anti-HSP60 and anti-p277 T cells, as well as with the appearance of circulating HSP65 cross-reactive antigens and anti-HSP65 antibodies $[3,4]$. In addition, although injection of anti-HSP65 or antip277 T-cell clones promote insulitis and diabetes in NOD mice, administering these cells after attenuation with $\gamma$-irradiation down-regulates the diabetogenic process [3]. Finally, a single dose of the p277 peptide in incomplete Freund's adjuvant reduces the in- 
cidence of diabetes in NOD mice, apparently by immunomodulatory effects on cytokine production [4-6]. The treatment with p277 also efficiently prevented development of autoimmune diabetes induced in C57BL/KsJ mice by low doses of streptozotocin [7].

In the mid 1990's, several groups identified a perchloric acid soluble ubiquitous $14 \mathrm{kDa}$ protein with pleiotropic properties [8-13] and having sequence homologies with HSP, Major Histocompatibility Complex-1 (MHC-1) Binding Protein, and with a functionally not yet identified group of proteins belonging to the so called YER057C/YIL051C/Y5GF family [8)]. We propose to unify the various names given by different authors for MFP14, which highlights its nature as a Multi Functional Protein and its molecular weight (14 kDa). The MFP14 was identified as a cytoplasmatic protein but under certain conditions, such as stress and neoplasia, it appears at the cell surface [14]. The possibility that an immunomodulatory effect could be involved in the capacity of MFP14 to prevent or modulate the development of several experimental tumors in mice, rats and hamsters $[14,15]$, and the above mentioned similarities with the HSP family led us to test the effects of MFP14 treatment in NOD mice. The prolonged treatment with MFP14 could indeed markedly reduce the incidence of the disease in these animals [16]. These promising preliminary observations prompted us to undertake a more extensive evaluation of the effects of MFP14 in autoimmune diabetes of NOD mice. We have now found that MFP14 prevents spontaneous Type I diabetes in NOD mice regardless of whether administration is started early (4 weeks of age) or late (12 weeks of age) during the prediabetic phase. Moreover, the clinical effect was associated with a marked reduction in the insulitis process compared with control animals. In addition, MFP14 also significantly delayed recurrence of hyperglycaemia in syngeneic islet-transplanted NOD mice. In vivo immunological studies suggest that the antidiabetogenic effects of MFP14 could be related to its capacity to skew the cytokine secretory profile of the treated mice from a Type I to a Type II subset, and could be causally related to its antidiabetogenic capacities.

\section{Materials and methods}

Animal and reagents. Female NOD mice were purchased from Charles River (Calco, Italy). The spontaneous incidence of diabetes in the females ranges between 70 and $80 \%$ by the age of 30 weeks. For the recurrence of disease experiments (see below) NOD mice maintained in a local colony (Biomedical Centre, Uppsala, Sweden) were used. The spontaneous incidence of hyperglycaemia is approximately $70 \%$ in the females in the latter colony. Male Sprague-Dawley rats were obtained from Biomedical Centre. The animals were maintained under standard laboratory conditions (non-specific pathogen free) with free access to food and water. During the study period of diabetes prevention the mice were screened for diabetes development twice a week by means of glycosuria followed, when positive, by measurement of glycaemia. Mice were diagnosed as diabetic when fasting glycaemia was above $12 \mathrm{mmol} / \mathrm{l}$ for 2 consecutive days.

Recombinant (r) MFP14 [17] was a gift of SICOR SpA (Rho, Italy). Hamster anti-mouse CD3 mAb was purchased from Pharmingen (San Diego, Calif., USA), and LPS (serotype 055:B5) was purchased from Sigma Chemicals (St.Louis, Mo., USA). RPMI 1640 (Sigma) was supplemented with $10 \%$ $\mathrm{vol} /$ vol fetal calf serum (Sigma). D-[U-14 C]glucose was from Amersham Pharmacia Biotech (Uppsala, Sweden). Recombinant human IL-1 $\beta$ was from Peprotech (London, UK). Solidphase ELISA kits for detection of mouse IL-4, IL-10, IFN- $\gamma$ and TNF- $\alpha$ were purchased from Pharmingen and for mouse IL-12 from Endogen (Cambridge, Mass., USA). Samples were run in duplicate according to the manufacturers' instructions. The lower limit of sensitivity of the assays were $5 \mathrm{pg} / \mathrm{ml}$ for IL-10 and IL-12, $10 \mathrm{pg} / \mathrm{ml}$ for IL-4 and IFN- $\gamma$ and $12 \mathrm{pg} / \mathrm{ml}$ for TNF- $\alpha$. Intra-assay and inter-assay coefficients of variations were within 15 and $20 \%$, respectively. To calculate mean values, blood samples with cytokine content lower than the limit of sensitivity of the assay were assigned the limit of sensitivity as a theoretical value.

Experimental design. Procedures involving animals and their care were in conformity with the institutional guidelines and in compliance with national and international laws for the Care and Use of laboratory animals.

Spontaneous Type I diabetes mellitus. Euglycaemic female NOD mice were randomly allocated into different groups receiving either MFP14, PBS or the heat-inactivated (by boiling for $45 \mathrm{~min}$ ) hi MFP14 starting at the $4^{\text {th }}$ or the $12^{\text {th }}$ week of age. Because insulitis is virtually absent in 4-week-old NOD mice and is actively ongoing in most animals at 12 weeks, this approach allowed us to investigate the effects of MFP14 treatment in both the early and late diabetogenic stages of the NOD mouse.

For the early prophylactic treatment, 4-week-old NOD mice were treated with MFP14, hi MFP14 or PBS until the age of 25 weeks (Fig. 1).

In a second set of experiments, the treatment was interrupted when the mice were 25 weeks old and the mice were screened for diabetes development until they were 50 weeks old (Fig. 2).

Finally, to evaluate the effects of MFP14-treatment on insulitis development, an experiment was conducted where 4week-old NOD mice were treated five consecutive times a week with either MFP14 or PBS until the age of 18 weeks. At this time point, the remaining euglycaemic mice from the three groups were killed and pancreatic specimens collected for histological examination of insulitis.

For the late prophylactic treatment, 12-week-old NOD mice were randomly divided into two experimental groups, one treated with MFP14 and the other with PBS. Pancreatic specimens for histological analysis of insulitis were collected from diabetic mice from the remaining euglycaemic mice killed at the end of the treatment (35 weeks).

Recurrence of diabetes (ROD) after syngeneic islet transplantation. Pancreatic glands were removed from 7-10 week-old euglycaemic male NOD mice and the pancreatic islets were isolated by a collagenase digestion technique [18]. The isets were kept free-floating in medium RPMI $1640+10 \%$ fetal calf serum for three days $\left(37^{\circ} \mathrm{C}\right.$ air $\left.+5 \% \mathrm{CO}_{2}\right)$ with a medium ex- 


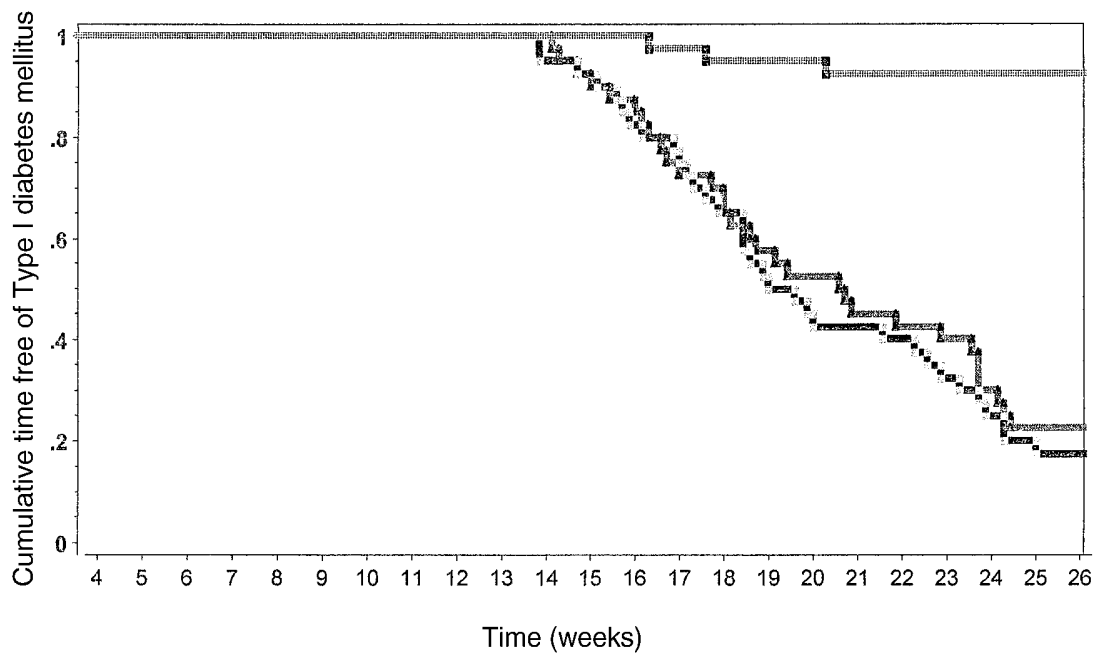

Fig. 1. Prevention of Type I diabetes mellitus in NOD mice by early prophylactic treatment with MFP14. Four-week-old NOD mice were treated with $25 \mu \mathrm{g}$ MFP14, hi-MFP14 or PBS five consecutive times a week until the age of 25 weeks

change after 2 days. Islets in groups of 600 were subsequently transplanted, under Avertin anaesthesia, beneath the left renal capsule of the spontaneously diabetic NOD mouse [19]. Islet transplantation was considered successful when the nonfasting blood glucose value declined to $12 \mathrm{mmol} / \mathrm{l}$ after 2-3 days. Blood glucose was measured daily from a tail vein (ExacTech blood glucose meter; Baxter Travenol, Deerfield, Ill., USA). Recurrence of autoimmune disease in the islet

Fig. 2. Prolonged treatment with MFP14 affords long-lasting protection against Type I DM development in NOD mice. Four-week old NOD mice were treated as described in the Legend to Figure 1 above with either $25 \mu \mathrm{g}$ MFP14 or PBS until the age of 25 weeks. At this time point treatment was interrupted and the mice were followed for diabetes development until the age of 50 weeks graft was defined as reversal of hyperglycaemia with a blood glucose of $12 \mathrm{mmol} / \mathrm{l}$ or more on two consecutive days. The transplanted diabetic mice were subjected to either daily PBS- or MFP14 (25 $\mu \mathrm{g}$ in $200 \mu \mathrm{l} \mathrm{PBS}$ intraperitoneally). The injections were commenced one day before islet implantation.

In vivo effects of MFP14 on anti-CD3 and/or LPS-induced increase in the blood levels of IL-4, IL-10, IL-12, IFN- $\gamma, T N F-\alpha$. Four-week-old female NOD mice were treated five consecutive times a week for 6 weeks with either $25 \mu \mathrm{g}$ MFP14 or PBS until $1 \mathrm{~h}$ before the injection with anti-mouse CD3 mAb or $100 \mathrm{ug}$ LPS. Blood samples, collected from individual mice at the time points indicated in the Legends to Figures 5 and 6, were allowed to clot at room temperature and serum was immediately separated by centrifugation at $1000 \mathrm{~g}$ and stored frozen until cytokine measurement.

Histological examination of pancreatic islets. This was performed in a blind fashion by an observer who was unaware of the treatment or the status of the mice as described in detail elsewhere [20]. At least 10 islets were counted for each pancreas. The degree of mononuclear cell infiltration was graded as follows: 0 , no infiltrate; 1 , periductular infiltrate; 2 , periislet infilrate; 3 , intraislet infiltrate; 4 , intraislet infiltrate associated with beta cell destruction. The mean score for each pancreas

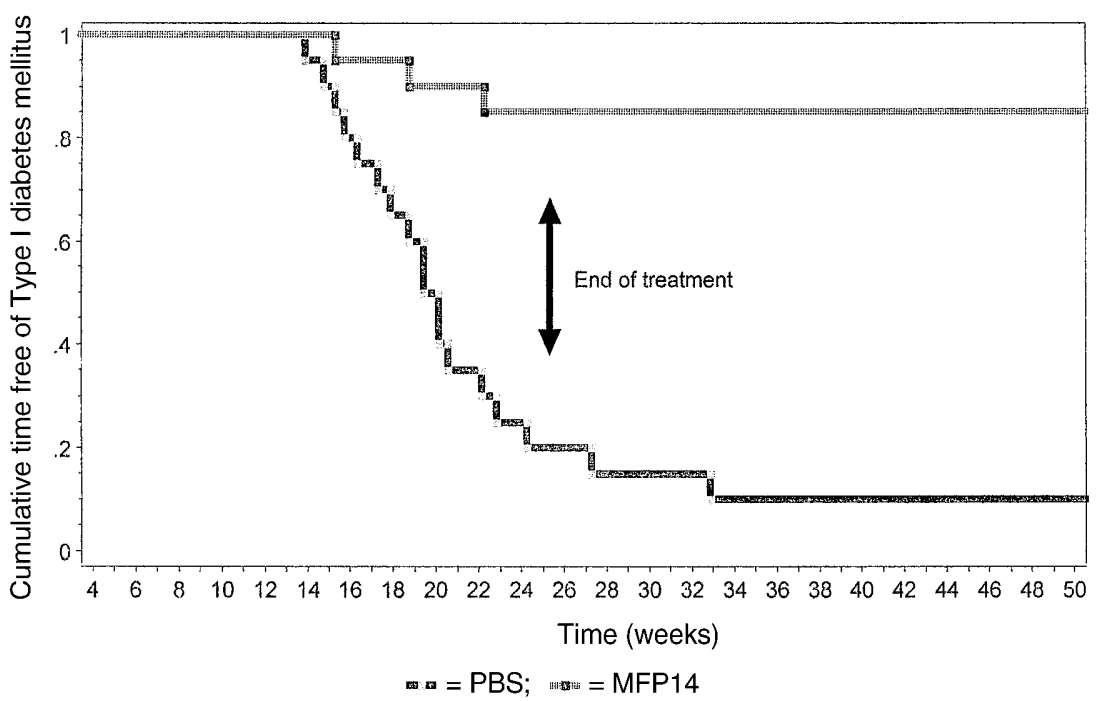




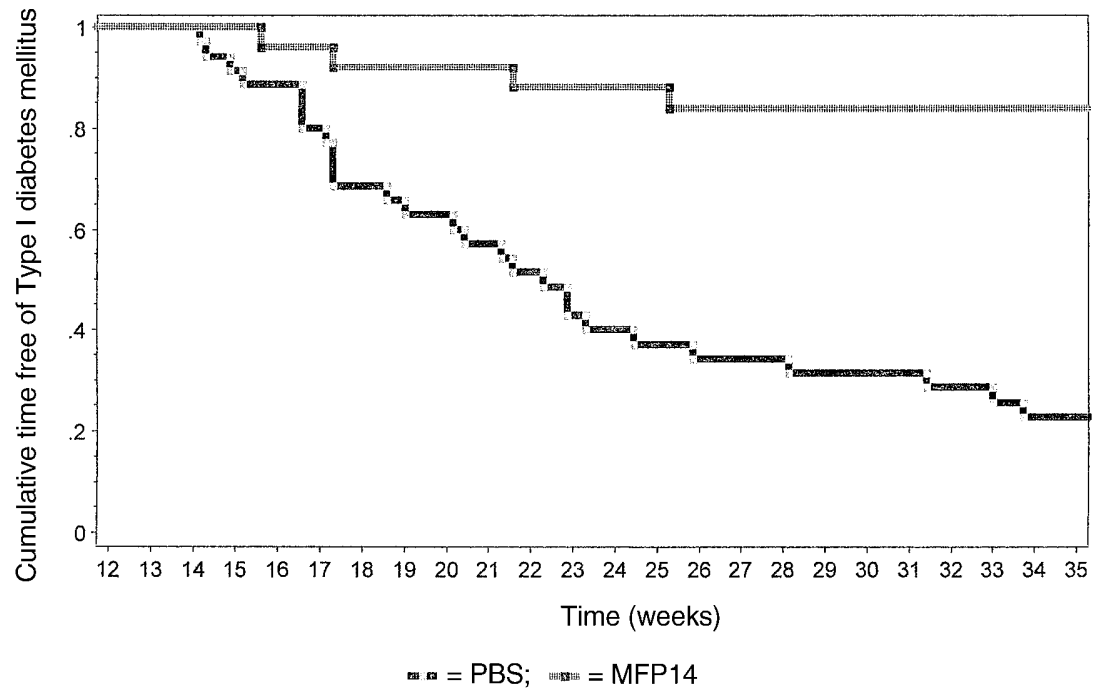

Fig. 3. Prevention of Type I diabetes mellitus in NOD mice by late prophylactic treatment with MFP14. Euglycaemic female NOD mice were treated five consecutive times a week i.p.with either $25 \mu \mathrm{g}$ MFP14 or PBS from the $12^{\text {th }}$ until the 25 week of age

was calculated by dividing the total score by the numbers of islets examined.

In vitro effects on rat pancreatic islets of IL-1 $\beta$ and MFP14 on islet glucose oxidation rate and nitrite production. Rat pancreatic islets were isolated and kept in tissue culture for 5-7 days before use [18]. Then islets in groups of 50 were transferred to new culture dishes containing medium RPMI $1640+10 \%$ fetal calf serum, MFP14 $(0.25$ or $1 \mathrm{mg} / \mathrm{ml})$, hi-MFP14, in the absence or presence of $25 \mathrm{U} / \mathrm{ml} \mathrm{r}$ human IL- $1 \beta$ for $48 \mathrm{~h}$. In these experiments MFP14 was added $1 \mathrm{~h}$ before the cytokine. Islet glucose oxidation rate was measured after addition of $\mathrm{D}$-[U$\left.{ }^{14} \mathrm{C}\right]$ glucose at $16.7 \mathrm{mmol} / \mathrm{l}$ glucose as described elsewhere [21]. Medium nitrite accumulation in the culture medium, as an indicator of nitric oxide production, was measured by the Griess reaction [22]. The detection limiy of the assay was $0.25 \mu \mathrm{mol} / \mathrm{l}$. One independent observation represents islets isolated from one rat.

\section{Results}

Lack of toxicity of MFP14. Long-term administration of MFP14 to NOD mice either from the age of 4 to 25 weeks or from the 12 to 35 weeks of age was apparently well tolerated by the animals as judged both from their clinical appearance and behaviour. In addition, the body weight of MFP14-treated animals was similar to that of control animals, and no differences were observed in both azotemia and transaminases values at the end of the study (data not shown). severity of insulitis in NOD mice. An increasing number of NOD mice treated with either saline $(33 / 40)$ or hi-MFP14 (31/40) developed diabetes by the age of 25 weeks (Fig. 1). In contrast, only 4 out of 40 NOD mice treated with MFP14 became hyperglycaemic at the same period of age $(p<0.0001$ vs both PBS and hi-MFP14-treated groups by Logrank (Mantel-Cox). Treatment with MFP14 three times a week on alternate days had a partial, though not significant effect on the development of the disease, 25/40 of the sotreated mice developing Type I diabetes with kinetics very similar to that of either PBS-treated mice or hiMFP14-treated mice (not shown).

To evaluate whether the antidiabetogenic effect of MFP14 was reversible or not upon treatment withdrawal, NOD mice were treated exactly as above with either MFP14 or PBS from the 4th until the 25 th week of age. The treatment was then discontinued and the remaining euglycaemic mice from the two groups were followed for diabetes development up to the 50th week of age. The data depicted in Figure 2 clearly confirms the preventive efficacy of MFP14 on diabetes development (3/20 diabetics among MFP14-treated mice vs $18 / 20$ vs PBS-treated control mice, $p<0.0001$ by Logrank (Mantel-Cox)). The long, perhaps life-lasting, duration of the effect is manifested by the fact that none of the MFP14treated mice, which were euglycaemic at the end of the treatment, became diabetic during the further 25 weeks of follow-up period.

In agreement with these clinical data, the insulitis score (IS) of the remaining euglycaemic NOD mice treated with MFP14 for 14 consecutive weeks from the age of 4 weeks $(n=15)$ was significantly milder than that of control NOD mice treated with PBS $(n=10) \quad($ mean $\quad \mathrm{IS} \pm \mathrm{SD}=0.7 \pm 0.3 \quad$ vs $2.2 \pm 1.2$, $p=0.0001$ by ANOVA).

Late prophylactic treatment with MFP14 prevents Type I DM development and blocks progression of in- 


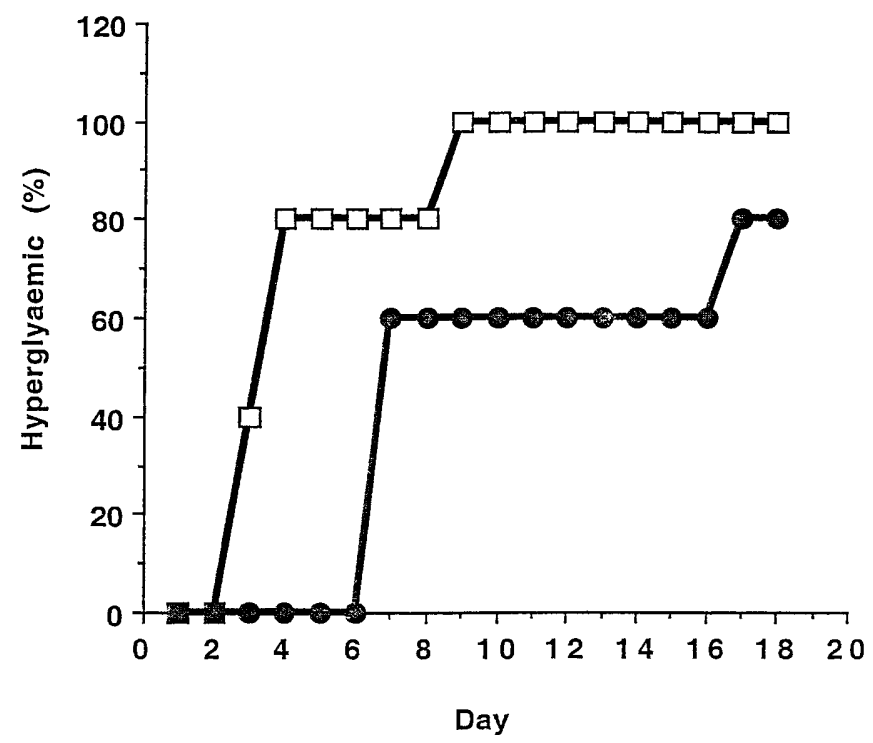

Fig. 4. MFP14 delays ROD after syngeneic islet transplantation in NOD mice. Islet transplanted diabetic recipients were treated with $25 \mu \mathrm{g} \operatorname{MFP} 14(\mathbf{\square}, \mathbf{O})$ or PBS $(\square, \bigcirc)$ starting from one day before transplantation and the treatment was continued daily until reversal of hyperglycaemia. In the control group the days of reversal were $3,3,4,4,9$ and in the MFP14 group 7, 7, 7, 17 and 18 or over. The animal over 18 was still normoglycaemic when sacrificed after 5 weeks. However, for the calculation of statistical analysis it was considered a reverter on day 18 when the treatment had been interrupted

sulitis in NOD mice. To ascertain whether MFP14 could also interfere with diabetes development when first administed later in life to NOD mice, another experiment was conducted where the drug was first given to euglycaemic animals at an older age (12 weeks), which is associated with histological signs of active ongoing insulitis [23, 24]. Control mice were treated with PBS. Treatment were given five consecutive times a week until the mice were 35 weeks of age. At this point, the remaining euglycaemic mice were killed and their pancreata specimens collected for histological evaluation of insulitis.

Even when applied a this late stage of prophylactic treatment MFP14 significantly reduced the cumulative incidence of Type I diabetes in NOD mice compared with control mice ( $4 / 25$ vs $27 / 35, p<0.0001$ by Logrank (Mantel-Cox)) (Fig. 3). The protection was also observed at the histological level as at the end of the study (age 35 weeks), the pancreatic islets from the 21 euglycaemic MFP14-treated mice showed significantly milder mononuclear cell infiltration than that observed in the 8 PBS-treated control mice (IS mean values $\pm \mathrm{SD} ; 2.1 \pm 1.2$ vs $3.5 \pm 2.1$, $p=0.032$ by ANOVA). Interestingly, the IS of the MFP14-treated mice was very similar to that found in 10 untreated euglycaemic 12 -week-old NOD mice $(1.9 \pm 1.1)$, that is the age when MFP14 treatment was instituted. This indicates that MFP14 has inhibit-

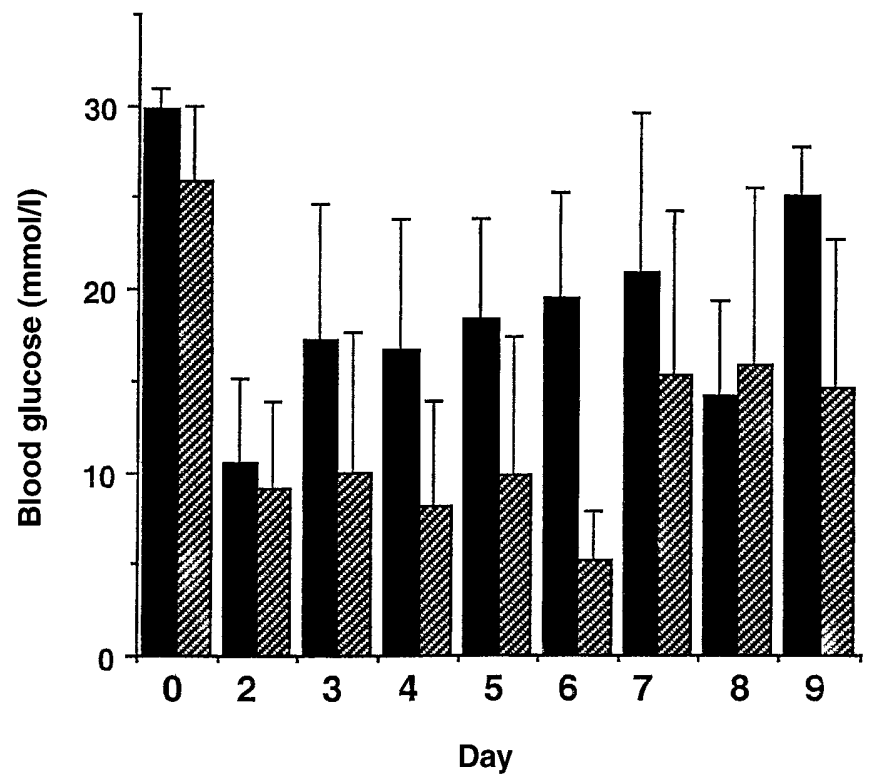

Fig. 5. Blood glucose levels in diabetic NOD mice transplanted with syngeneic islets from euglycaemic donors by MFP14. Blood glucose levels $( \pm$ SD) from PBS $(\square)$ and MFP14 (V/A) treated NOD mice for up to 9 days after syngeneic islet transplantation

ed further progression of insulitis towards more aggressive and beta-cell destructive forms.

MFP14 delays ROD in NOD mice after syngeneic islet transplantation. The five control mice treated with PBS only reverted to hyperglycaemia within $4.6 \pm 2.46$ (mean $\pm \mathrm{SD}$ ) days after syngeneic islet transplantation (Fig. 4) whereas, it took a significantly longer time for this to occur in the five mice treated with MFP14 that first showed hyperglycaemia after $11.2 \pm 5.81$ days $(p=0.048$ by ANOVA $)$. Figure 5 shows the blood glucose concentrations (means \pm $\mathrm{SD}$ ) in the two groups for up to 9 days after islet transplantation.

MFP14 modulates the blood levels of IL-4, IL-10, IL$12, I F N-\gamma$ and $T N F-\alpha$ induced by in vivo injection with anti-CD3 $m A b$ or LPS. In vivo experiments were carried out to evaluate whether the antidiabetogenic effects of MFP14 could depend on or be associated with immunomodulatory effects. In particular we studied the effects of MFP14 on the anti-CD3 or LPS-induced blood levels of Type I (IFN- $\gamma$, IL-12, TNF- $\alpha$ ) and Type II (IL-4, IL-10) cytokines, which could be involved in Type I diabetes pathogenesis [25-28]. Ten week-old NOD mice were injected with either anti-CD3 mAb or LPS $1 \mathrm{~h}$ after a 6 week-treatment period with MFP14 or PBS. Because anti$\mathrm{CD} 3 \mathrm{mAb}$, that reacts with the $25 \mathrm{kDa} \varepsilon$ chain of the T-cell receptor associated CD3 complex, induces $\mathrm{T}$ cells to release several Type I and Type II cytokines (IL-4, IL-10, IFN- $\gamma$ TNF- $\alpha$ ), this approach allowed 

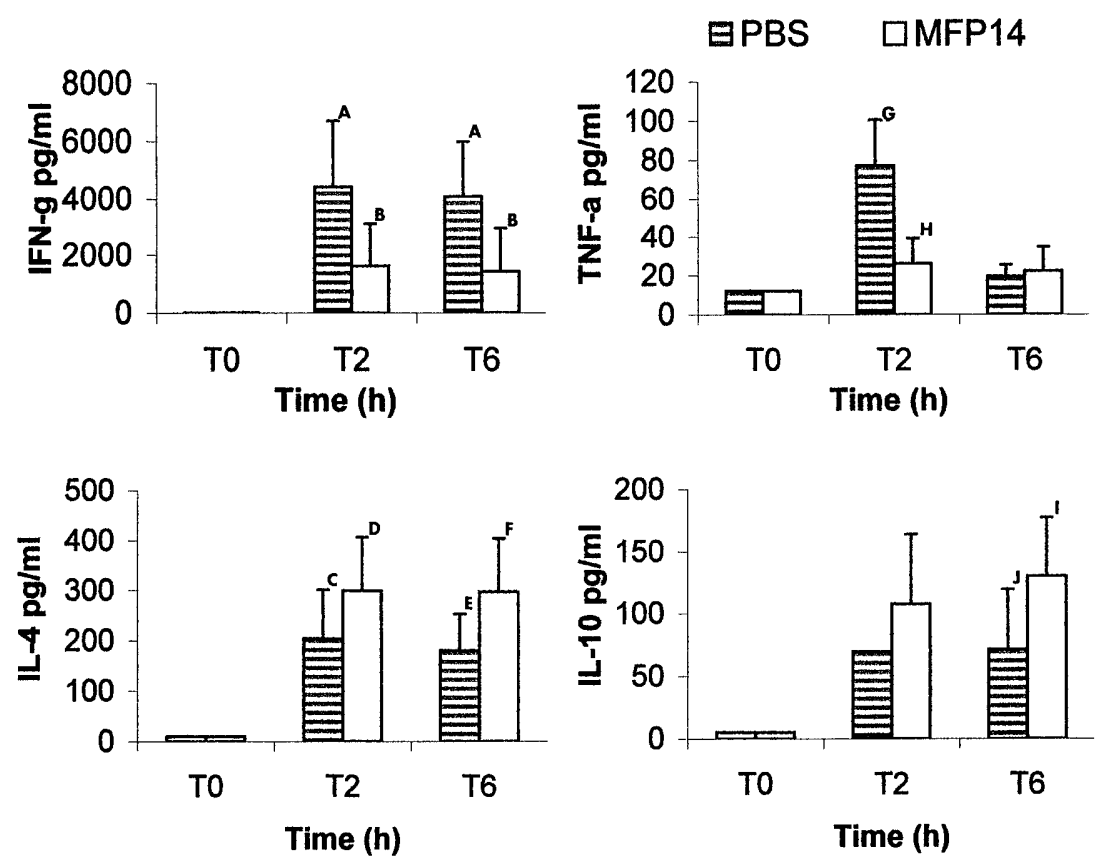

Fig. 6. Modulation by MFP14 of anti-CD3 mAb- induced blood levels of IFN-g, IL-4, TNF- $\alpha$ and IL-10. Four week-old female NOD mice were treated five consecutive times a week for 6 weeks with either $25 \mu \mathrm{g}$ MFP14 ( $\square$ ) or PBS (咠) until $1 \mathrm{~h}$ before the injection with $10 \mu \mathrm{g}$ of anti-mouse CD3 mAb. Blood samples were collected from 15 mice for each group sacrificed at T0, just before anti-CD3 $\mathrm{mAb}$-challenge and 2 and $6 \mathrm{~h}$ thereafter. $\mathrm{B}$ vs $\mathrm{A}, p<0.0001$; D vs $\mathrm{C}, p=0.018, \mathrm{~F}$ vs $\mathrm{E}$, $p=0.002 ; \mathrm{H}$ vs $\mathrm{G}, p<0.001 ; \mathrm{J}$ vs $\mathrm{I}, p<0.0001$ by ANOVA with Bonferroni's adjustement

us to selectively study the impact of MFP14 treatment on the T-cell secretory profile of NOD mice. On the other hand, we used the specific ability of LPS to provoke cytokine production from the macrophages to study the in vivo influence of MFP14 treatment on the release from these cells of IL-12, a cytokine which plays a key role in the polarization of a Type I cytokine response by up-regulating IFN- $\gamma$ production [29].

Before anti-CD3 mAb or LPS injection (T0), the blood levels of IL-4, IL-10, IFN- $\gamma$ and TNF- $\alpha$ were all below the limit of sensitivity of the assays regardless of whether NOD mice were treated with MFP14 or PBS (Fig.6). In contrast, as previously reported [30], IL-12 could be detected at T0 at low levels in the blood of 4 out of 15 NOD mice (Fig. 7). The cytokines were all massively released with different kinetics in the blood of the mice 2 and/or $6 \mathrm{~h}$ after challenge with anti-CD3 mAb or LPS. Figure 6 and 7 show the marked differences observed in the cytokine circulating profile between MFP14-treated and PBS-treated NOD mice, the former having lower blood levels of IFN- $\gamma$, TNF- $\alpha$ and IL-12 and higher blood levels of IL-4 and IL-10 than the latter at 2

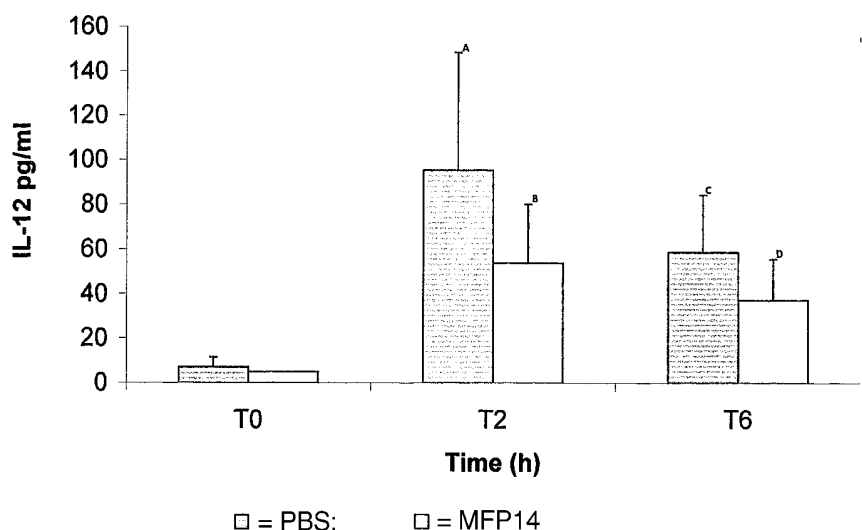

Fig. 7. Modulation by MFP14 of LPS-induced blood levels of IL-12. Four week-old female NOD mice were treated exactly as described in the Legend to Figure 5 until the age of 10 weeks with either MFP14 ( $\square$ ) or PBS (目) until $1 \mathrm{~h}$ before the injection with $100 \mu \mathrm{g}$ LPS. Blood samples were collected from 15 mice for each group sacrificed at T0, just before LPS-challenge and 2 and $6 \mathrm{~h}$ thereafter. $\mathrm{B}$ vs $\mathrm{A}, p=0.011$; D vs $\mathrm{C}$, $p=0.013$ by ANOVA with Bonferroni's adjustement

and/or 6 hours after anti-CD3 mAb or LPS injection.

MFP14 does not influence IL-1 $\beta$-induced effects on pancreatic islets in vitro. In order to test if MFP14 could directly affect cytokine effects at the islet level, we investigated whether MFP14 could counteract IL$1 \beta$ actions on isolated rat pancreatic islets. Exposure for $48 \mathrm{~h}$ to $\mathrm{r}$ human IL- $1 \beta$ induced a marked increase in medium nitrite formation (Fig. 8). This was not affected by either $1 \mathrm{mg} / \mathrm{ml}$ MFP14 or hi-MFP14. Neither at the concentration of $0.25 \mathrm{mg} / \mathrm{ml}$ the protein influenced the increase in nitrite production (data not 


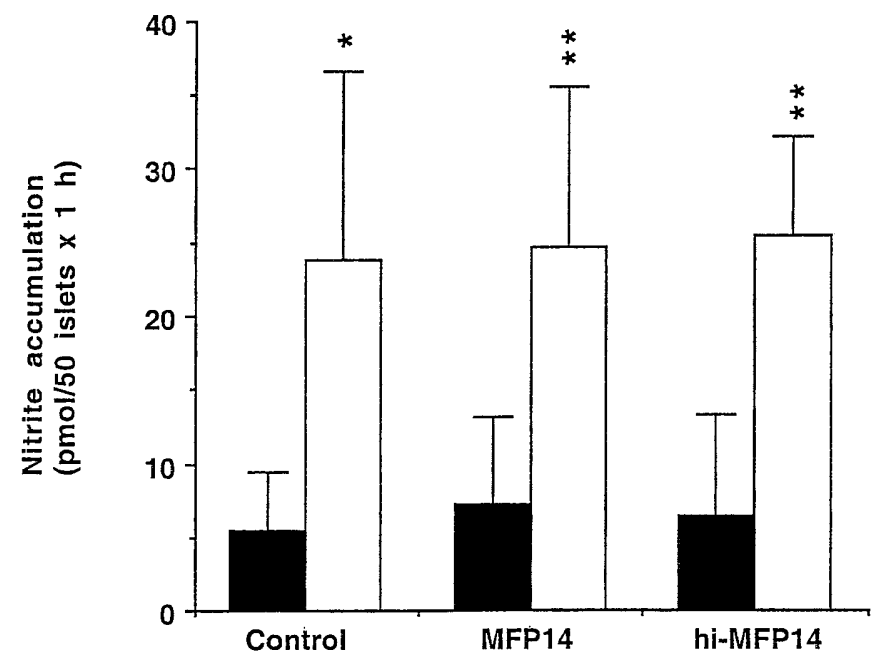

Fig. 8. MFP14 does not influence IL- $\beta$-induced medium nitrite accumulation in rodent pancreatic islets. Nitrite was measured as described in the Methods section. Rat islets were either non cytokine exposed $(\boldsymbol{\square})$ or exposed to $25 \mathrm{U} / \mathrm{ml} \mathrm{r}$ human IL-1 $\beta(\square)$ for $48 \mathrm{~h}$ with or without addition of $1 \mathrm{mg} / \mathrm{ml} \mathrm{MFP14}$ or hi-MFP14. Values are means \pm SD for 6 experiments. * and $* *$ denote $p<0.05$ and $p<0.01$ vs corresponding controls by ANOVA

shown). Exposure to $r$ human IL-1 $\beta$ impaired the islet glucose oxidation rate at $16.7 \mathrm{mmol} / \mathrm{l}$ glucose, and this was neither prevented by the presence of $1 \mathrm{mg} /$ ml MFP14 nor hi-MFP14 (Fig. 9). Addition of $1 \mathrm{mg} /$ ml MFP14 or hi-MFP14 alone did not alter basal nitrite formation or the islet glucose oxidation rate.

\section{Discussion}

We have demonstrated here that prolonged treatment with MFP14 dose-dependently prevents both clinical and histological signs of Type I diabetes mellitus in NOD mice. The drug displayed an almost equal efficiency regardless of whether it was administered upon an early prophylactic regimen, or as a late prophylactic intervention. MFP14 was also capable of significantly delaying ROD in NOD mice after syngeneic islet transplantation. In vivo studies revealed that MFP14 profoundly modulated the cytokine secretory profile of NOD mice, favouring a Type II rather than Type I phenotype following in vivo injections with anti-CD3 $\mathrm{mAb}$ or LPS.

The two cytokine subsets are tightly regulated, with Type I cytokines often controlling and antagonizing the action of Type II cytokines and vice versa [31]. The MFP14-induced cytokine shift towards a Type II phenotype could, therefore, be causally related to its antidiabetogenic effects. In fact, several lines of evidence indicate both spontaneous Type I diabetes mellitus and ROD after syngeneic islet transplantation to be Type I cytokine dependent events in NOD mice [25-28, 31-40]. It is noteworthy, however,

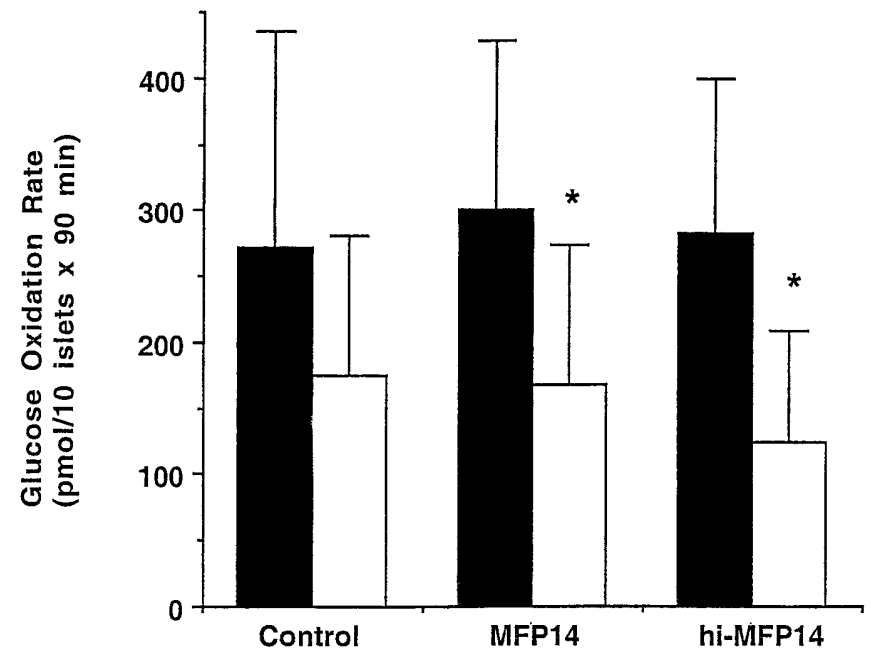

Fig. 9. Failure of MFP14 to counteract rhIL- $1 \beta$-induced inhibition of glucose oxidation rate in rodent pancreatic islets. The islet glucose oxidation was measured as described in the Methods section. Islets were exposed to $r$ human IL-1 $\beta$ and MFP14 as described in the Legend's to Figure 8 . Values are means \pm SD for 8 experiments. * denotes $p<0.05$ vs corresponding control mice by ANOVA

that whilst IL-4 and IL-10 are each in themselves capable of preventing spontaneous Type I diabetes mellitus in NOD mice [25-28], they need to be administered together to prolong graft survival after syngeneic islet transplantation [36]. This indicates the more aggressive nature of the IL-10 versus the IL-4 type of beta-cell destructive immune process. The clearcut capacity of MFP14 to delay the rejection of syngeneic islet grafts further demonstrates the powerful immunomodulatory properties of this protein.

Besides being directly destroyed by $\mathrm{T}$ cells and macrophages by cytotoxic, perforin-mediated mechanisms, the insulin-producing cells are also thought to be damaged by cytokines (IL- $1 \beta$, TNF- $\alpha$, IFN- $\gamma$ ), free radicals and nitric oxide that are produced in the vicinity of the beta cells during the autoimmune attack [36, 41-43 for reviews]. Thus, MFP14 could have also exerted its action by counteracting cytokine and nitric-oxide-mediated toxic events This possibility is, however, not supported by our present finding that the addition of MFP14 to rodent pancreatic islets challenged in vitro with IL- $1 \beta$ neither prevented inhibition of glucose oxidation rate nor increased nitrite accumulation in the medium. It can, however, not be excluded that MFP14 influences subsequent steps of beta-cell death induced by IL- $1 \beta$ and/or nitric oxide such as apoptosis, which has been proposed as one of the potential mode of beta cell death in Type I diabetes mellitus [44].

Two observations deserve attention when considering the modulatory effects of MFP14 on the course of Type I diabetes in NOD mice. First, MFP14 not only markedly reduced the incidence of diabetes, 
but it also kept the mice free from disease for as long as 25 weeks after the treatment had been interruped. This observation offers important clues for the clinical setting: short-term treatment with MFP14 could confer long-lasting protection against disease development. It also offers insights into MFP14's mechanistic mode of action. In fact, the long-lasting antidiabetogenic protection offered by MFP14 could presumably be primarily because of the elimination of autoreactive effectors or the induction of suppressor cells. Whatever the mechanism, the long-term protection produced by MFP14 closely resembles that induced in these animals by exogenously-administered Type II cytokines like IL-4 and IL-13, which also persists for a long time after treatment withdrawal [20, 25]. By contrast, Type I cytokine inhibitors such as anti-IFN- $\gamma$ antibodies, the IFN- $\gamma$ soluble receptor [23] or the r IL-12p40 [38], induce a short-lasting protection that is reversed after drug treatment ceases. These observations, together with the induction of Type II cytokine profile in MFP14-treated NOD mice suggest that by up-regulating Type II cytokine production, MFP14 has activated antidiabetogenic pathways similar to those induced by the administration of Type II cytokines themselves. Second, MFP14 successfully suppressed morphological and clinical signs of Type I diabetes in NOD mice regardless of whether it was administered at an early or late stage of the prophylactic regimen, e.g. in mice that though euglycaemic had already developed actively ongoing insulitis. This latter finding is clinically relevant because, at present, preventive immunotherapy in humans at risk for developing Type I diabetes can only be performed in individuals selected on the basis of seroimmunological (ICA, anti-GAD antibodies) and metabolic (reduction of glucose tolerance) parameters presumably associated with actively ongoing beta-cell destruction [45]. Taken together, these present findings suggest MFP14 is worthy of consideration as a possible candidate for the immunopharmacological prevention and could be valuable in the early treatment of human Type I diabetes.

Acknowledgements. This work was partly supported by the Swedish MRC, Swedish Diabetes Association and the Juvenile Diabetes Foundation International. We are grateful for skilled technical assistance of I.-B. Hallgren, A. Nordin and E. Törnelius.

\section{References}

1. Bach JF (1994) Insulin-dependent diabetes mellitus as an autoimmune disease. Endocr Rev 15: 516-422

2. Roep BO (1996) T-ceII responses to autoantigens in IDDM. The search for the holy grail. Diabetes 45: 1147-1156

3. Elias D, Reshef T, Birk OS, Van der Zee R, Walker MD, Cohen IR (1991) Vaccination against autoimmune mouse diabetes in young NOD mice with a T-ceII epitope of the human $65-\mathrm{kDa}$ heat shock protein. Proc Natl Acad Sci USA 88: 3088-3091

4. Elias D, Cohen IR (1994) Peptide therapy for diabetes in NOD mice. Lancet 343: 704-706

5. Elias D, Cohen IR (1995) Treatment of autoimmune diabetes and insulitis in NOD mice with heat shock protein 60 peptide p277. Diabetes 44: 1132-1138

6. Elias D, Meilin A, Ablamutis V et al. (1997) HSP60 peptide therapy of NOD mouse diabetes induces a Type- 2 cytokine burst and down regulates autoimmunity to various $\beta$-cell antigens. Diabetes 46: 758-764

7. Elias D, Cohen IR (1996) The HSP60 peptide p277 arrests the autoimmune diabetes induced by the toxin streptozotocin. Diabetes 45: 1168-1172

8. Ceciliani F, Faotto F, Negri A et al. The primary structure of UK-114 tumor antigen. FEBS Lett 1996. 393: 147-150

9. Levy-Favetier F, Cuisset L, Nedelec B, Tichonicky L, Kruh J, Delpech M. (1993) Characterization, purification and cDNA cloning of rat perchloric-acid-soluble $23 \mathrm{kDa}$ protein present in liver and kidney. Eur J Biochem 212: 665-673

10. Oka T, Tsuji H, Noda C et al. (1995) Isolation and characterization of a novel perchloric acid-soluble protein inhibiting cell-free protein synthesis. J Biol Chem 270: 30060-30067

11. Schmiedeknecht G, Kerkhoff C, Orso E et al. (1996) Isolation and characterization of a $14.5-\mathrm{kDa}$ trichloroaceticacid-soluble translational inhibitor protein from human monocytes that is upregulated upon cellular differentiation. Eur J Biochem 241: 339-351

12. Schmiedeknecht G, Buchler C, Schmitz G (1997) A bidirectional promoter connects the p14.5 gene to the gene for Rnase P and Rnase MRP protein subunit hPOP1. Biochem Biophys Res Commun 241: 59-67

13. Melloni E, Michetti M, Salamino F, Pontremoli S (1998) Molecular and functional properties of a calpain activator protein specific for $\mu$-isoforms. J Biol Chem 273: 12827-12831

14. Bartorelli A, Bussolati B, Millesimo M, Gugliotta P, Bussolati G (1996) Antibody-dependent cytotoxic activity on human cancer cells expressing UK-114 tumor membrane antigen. Int J Oncol 8: 543-548

15. Racca S, Di Carlo F, Bartorelli A, Bussolati B, Bussolati G (1997) Growth inhibition of DMBA-induced rat mammary carcinomas by UK-114. Virchows Arch 431: 323-328

16. Panerai AE, Sacerdote P, Bianchi M et al. (1999) Chronic administration of UK-114, a multifunctional emerging protein, modulates the Th1/Th2 cytokine pattern and experimental autoimmune diseases. Ann NY Acad Sci 876: 229-235

17. Colombo I, Ceciliani F, Ronchi S, Bartorelli A, Berra B (1998) cDNA cloning and Escherichia coli expression of MFP14 tumor antigen. Biochim Biophys Acta 1442: 49-59

18. Sandler S, Andersson A, Hellerström C (1987) Inhibitory effects of interleukin 1 on insulin secretion, insulin biosynthesis, and oxidative metabolism of isolated rat pancreatic islets. Endocrinology 121: 1424-1431

19. Sandberg JO, Eizirik DL, Sandler S (1997) IL-1 receptor antagonist inhibits recurrence of disease after syngeneic islet transplantation to spontaneously diabetic non-obese diabetic (NOD) mice. Clin Exp Immunol 108: 314-317

20. Zaccone P, Phillips J, Conget I et al. (1999) Interleukin-13 prevents autoimmune diabetes in NOD mice. Diabetes 48 : $1522-1528$

21. Andersson A, Sandler S (1983) Viability test of cryopreserved endocrine pancreatic cells. Cryobiology 20: 161-168 
22. Green LC, Wagner DA, Goglowski J, Skipper PL, Wishnok JS, Tannenbaum SR (1982) Analysis of nitrate, nitrite and [15 N]nitrate in biological fluids. Anal Biochem 126: 131-138

23. Nicoletti F, Zaccone P, Di Marco R et al. (1996) The effects of a nonimmunogenic form of murine soluble interferongamma receptor on the development of autoimmune diabetes in NOD mouse. Endocrinology 138: 281-288

24. Lampeter EF, Signore A, Gale EA, Pozzilli P (1989) Lessons from the NOD mouse for the pathogenesis and immunotherapy of human Type I (insulin-dependent) diabetes mellitus. Diabetologia 32: 703-708

25. Rapoport MJ, Jaramillo A, Zipris D et al. (1993) Interleukin-4 reverses $\mathrm{T}$ cell proliferative unresponsiveness and prevents the onset of diabetes in nonobese diabetic mice. J Exp Med 178: 87-99

26. Cameron MJ, Arreaza GA, Zucker P et al. (1997) IL-4 prevents insulitis and insulin-dependent diabetes mellitus in nonobese diabetic mice by potentiation of regulatory $\mathrm{T}$ helper-2 cell function. J Immunol 159: 4686-4692

27. Pennline KJ, Roque-Gaffney E Monahan M (1994) Recombinant human interleukin-10 prevents the onset of diabetes in nonobese diabetic mice. Clin Immunol Immunopathol 71: 169-175

28. Nitta Y, Tashiro F, Tokui M et al. (1998) Systemic delivery of interleukin-10 by intramuscular injection of expression plasmid DNA prevents autoimmune diabetes in nonobese diabetic mice. Hum Gene Ther 9: 1710-1717

29. Trembleau S, Germann T, Gately MK, Adorini L (1995) The role of IL-12 in the induction of organ-specific autoimmune diseases. Immunol Today 16: 383-386

30. Nicoletti F, Zaccone P, Conget I et al. (1999) Early prophylaxis with recombinant human interleukin-11 prevents spontaneous diabetes in NOD mice. Diabetes 48: 2333-2339

31. Rabinovitch A (1998) An update on cytokines in the pathogenesis of insulin-dependent diabetes mellitus. Diabetes Metab Rev 14: 129-151

32. Rabinovitch A, Suarez-Pinzon WL, Sorensen O, Bleackley RC, Power RF (1995) IFN-gamma gene expression in pancreatic islet-infiltrating mononuclear cells correlates with autoimmune diabetes in nonobese diabetic mice. J Immunol 154: 4874-4882

33. Rabinovitch A, Sorensen O, Suarez-Pinzon WL, Power RF, Rajotte RV, Bleackley RC (1994) Analysis of cytokine mRNA expression in syngeneic islet grafts of NOD mice: interleukin-2 and interferon-gamma mRNA expression correlate with graft rejection and interleukin-10 with graft survival. Diabetologia 37: 833-837

34. Sheadeh N, La Rosa F, Lafferty KJ (1993) Altered cytokine activity in adjuvant inhibition of autoimmune diabetes. J Autoimmun 6: 291-300

35. Rabinovitch A (1994) lmmunoregulatory and cytokine imbalances in the pathogenesis of IDDM. Therapeutic intervention by immunostimulation? Diabetes 43: 613-621

36. Rabinovitch A, Suarez-Pinzon WL, Sorensen O, Bleackley RC, Power RF, Rajotte RV (1995) Combined therapy with interleukin-4 and interleukin-10 inhibits autoimmune diabetes recurrence in syngeneic islet-transplanted nonobese diabetic mice. Analysis of cytokine mRNA expression in the graft. Transplantation 60: 368-374

37. Yang XD, Tisch R, Singer SM et al. (1994) Effect of tumor necrosis factor alpha on insulin-dependent diabetes mellitus in NOD mice. I The early development of autoimmunity and the diabetogenic processw. J Exp Med 180: 995-1004

38. Trembleau S, Penna G, Gregori S, Gately MK, Adorini L (1997) Deviation of pancreas-infiltrating cells to Th2 by interleukin-12 antagonist administration inhibits autoimmune diabetes. Eur J Immunol 27: 2330-2339

39. Nicoletti F, Di Marco R, Zaccone P et al. (1999) Endogenous interleukin-12 only plays a key pathogenetic role in non-obese diabetic mouse diabetes during the very early stage of the disease. Immunology 97: 367-370

40. Yasuda H, Nagata M, Arisawa K et al. (1998) Local expression of immunoregulatory IL-12p40 gene prolonged syngeneic islet graft survival in diabetic NOD mice. J Clin Invest 102: $1807-1814$

41. Sandler S, Eizirik DL, Svensson C, Strandell E, Welsh M, Welsh N (1991) Biochemical and molecular actions of interleukin-1 on pancreatic beta cells. Autoimmunity 10: 241-253

42. Kolb H, Kolb-Bachofen V, Roep BO (1995) Autoimmune versus inflammatory Type I diabetes: a controversy? Immunol Today 16: 170-172

43. Kay TW, Thomas HE, Harrison LC, Allison I (2000) The beta cell in autoimmune diabetes: many mechanisms and pathways of loss. Trends Endocrinol Metab 11: 11-15

44. Mauricio D, Mandrup-Poulsen T (1998) Apoptosis and the pathogenesis of IDDM: a question of life and death. Diabetes 47: 1537-1543

45. Nicoletti F, Meroni PL, Bendtzen K (1996) Fusidic acid and insulin-dependent diabetes mellitus. Autoimmunity 24: 187-197 